\title{
Recent Insight on the Management of Lupus Erythematosus Alopecia
}

This article was published in the following Dove Press journal:

Clinical, Cosmetic and Investigational Dermatology

\section{Karishma Desai \\ Mariya Miteva}

Dr. Phillip Frost Department of Dermatology and Cutaneous Surgery, University of Miami Miller School of

Medicine, Miami, FL, USA
Correspondence: Karishma Desai Dr. Phillip Frost Department of Dermatology and Cutaneous Surgery, University of Miami Miller School of Medicine, 1600 N.W. 10th Ave., RMSB Building Room 2023C, Miami, FL, 33I36, USA

Tel + I $305243-5523$

$\mathrm{Fax}+1305243-5810$

Email kdesai66@med.miami.edu

\begin{abstract}
Lupus erythematosus (LE) is a chronic autoimmune condition with a wide spectrum of clinical presentations. Alopecias, both non-scarring and scarring, frequently occur in the context of LE and can assume several different patterns. Furthermore, alopecia occurring with LE may be considered LE-specific if LE-specific features are present on histology; otherwise, alopecia is considered non-LE-specific. Non-scarring alopecia is highly specific to systemic LE (SLE), and therefore has been regarded as a criterion for the diagnosis of SLE. Variants of cutaneous LE (CLE), including acute, subacute, and chronic forms, are also capable of causing hair loss, and chronic CLE is an important cause of primary cicatricial alopecia. Other types of hair loss not specific to LE, including telogen effluvium, alopecia areata, and anagen effluvium, may also occur in a patient with lupus. Lupus alopecia may be difficult to treat, particularly in cases that have progressed to scarring. The article summarizes the types of lupus alopecia and recent insight regarding their management. Data regarding the management of lupus alopecia are sparse and limited to case reports, and therefore, many studies including in this review report the efficacy of treatments on CLE as a broader entity. In general, for patients with non-scarring alopecia in SLE, management is aimed at controlling SLE activity with subsequent hair regrowth. Topical medications can be used to expedite recovery. Prompt treatment is crucial in the case of chronic CLE due to potential for scarring and irreversible damage. First-line therapies for CLE include topical corticosteroids and oral antimalarials, with or without oral corticosteroids as bridging therapy. Second and third-line systemic treatments for CLE include methotrexate, retinoids, dapsone, mycophenolate mofetil, and mycophenolate acid. Additional topical and systemic medications as well as physical modalities used for the treatment of lupus alopecia and CLE are discussed herein.
\end{abstract}

Keywords: discoid, hair loss, cicatricial, scarring, non-scarring

\section{Introduction}

Lupus erythematosus (LE) is a chronic autoimmune condition with a wide spectrum of clinical presentations, ranging from isolated cutaneous lesions (cutaneous lupus erythematosus or CLE) to systemic disease (systemic lupus erythematosus or SLE) that can involve almost any organ system. ${ }^{1-3}$ Alopecias, both non-scarring and scarring, frequently occur in the context of $\mathrm{LE}^{4}$ and can assume several different patterns. ${ }^{5-9}$ Hair loss has been noted in up to $85 \%$ of SLE patients. ${ }^{7,8}$ In fact, nonscarring alopecia has been included as a criterion for the diagnosis of SLE according to the latest Systemic Lupus International Collaborating Clinics (SLICC) classification criteria based on its high specificity to SLE at $95.7 \% .{ }^{5,10}$ Chronic CLE is an important cause of primary cicatricial alopecia, ${ }^{11}$ the classical example being scalp discoid LE. ${ }^{5}$ 
Other types of hair loss not specific to LE may also occur. ${ }^{5,8}$ Alopecia occurring in the context of LE may be difficult to treat, particularly in cases that have progressed to scarring. The objective of this review article is to summarize recent insight regarding the management of lupus alopecia.

\section{Materials and Methods}

We ran a literature search of PubMed/MEDLINE that included studies, reviews, and case reports/series addressing treatments for lupus erythematosus alopecia. Keywords used in various combinations in the literature search included: lupus erythematosus, alopecia, cutaneous, scarring, cicatricial, non-scarring, hair, treatment, therapy, management. Relevant articles published in English were selected based on recent date of publication, report of high-quality data, and/or specific mention of lupus alopecia.

\section{Types of LE Alopecia}

Alopecias occurring with LE may be non-scarring or scarring, and they may be considered LE-specific or non-LEspecific. Alopecias are considered LE-specific when they exhibit LE-specific features on histology. ${ }^{5}$

\section{LE-Specific Alopecia Discoid Lupus Erythematosus (DLE)}

DLE is a variant of chronic CLE and a common cause of scarring alopecia. ${ }^{5,12,13}$ DLE is considered as a separate criterion from non-scarring alopecia in the SLICC classification criteria. ${ }^{5,10}$ Though DLE lesions are non-scarring in early stages, they can progress towards permanent scarring and result in irreversible hair loss. ${ }^{2,5,14}$

DLE is characterized clinically by erythematous, scaly papules and plaques with follicular plugging, hypo- and hyperpigmentation, variable atrophy, and telangiectasia (Figure 1A). ${ }^{2,11,14}$ We have described cases presenting as brown patches without atrophy or scarring that may be confused with melanocytic lesions, especially if presenting as individual lesions ${ }^{15}$ (Figure 1B). This phenotype may be similar to the hyperpigmented canine generalized discoid LE and may have a better prognosis regarding progression. $^{16}$ Lesions may be pruritic, tender, or burning. ${ }^{5,11}$ Trichoscopy exam should start with dry trichoscopy as using an immersion fluid hydrates the scale. Trichoscopy reveals thick arborizing vessels, follicular keratotic plugs, follicular red dots, peripilar scale, and peripilar erythema ${ }^{5,11,17}$ (Figure 2). Blue gray speckled dots and blue-white veil are two features observed in patients with Fitzpatrick skin type IV-VI. ${ }^{18,19}$ Histological features include vacuolar interface alteration of the dermoepidermal junction and the follicular epithelium, perivascular and periadnexal lympho-plasmacytic infiltrate, thickening of the basement membrane, pigmentary incontinence, reduced sebaceous glands, increased dermal mucin, and follicular hyperkeratosis. ${ }^{2,11,14}$ The inflammation may target both the upper and lower portions of the hair follicle, eventually resulting in follicular destruction, fibrosis, and follicular dropout on histology. ${ }^{14,20}$ Horizontal sections reveal two common patterns: alopecia areata (AA)-like pattern (52\%)
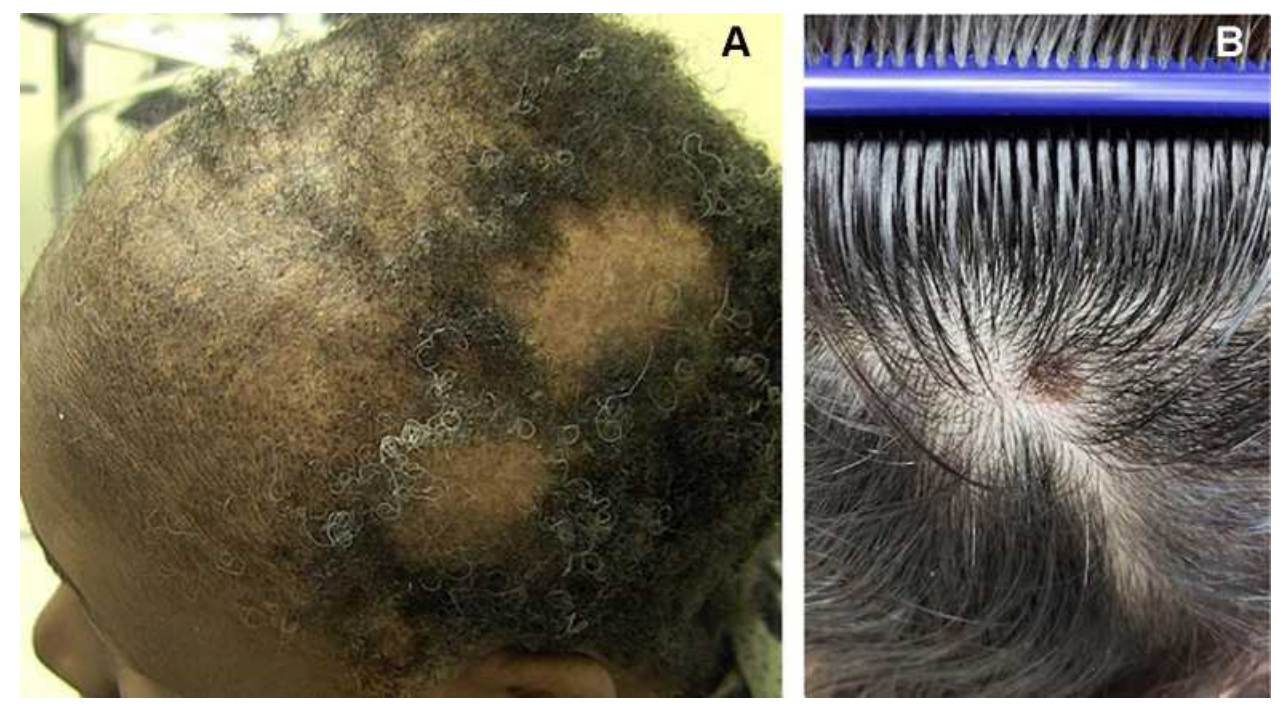

Figure I (A) Discoid lupus erythematosus (DLE) may present as patchy areas with atrophy and hyperpigmentation. (B) Individual hyperpigmented patches and plaques in discoid lupus erythematosus (DLE) may lack atrophy and simulate pigmented lesions. 


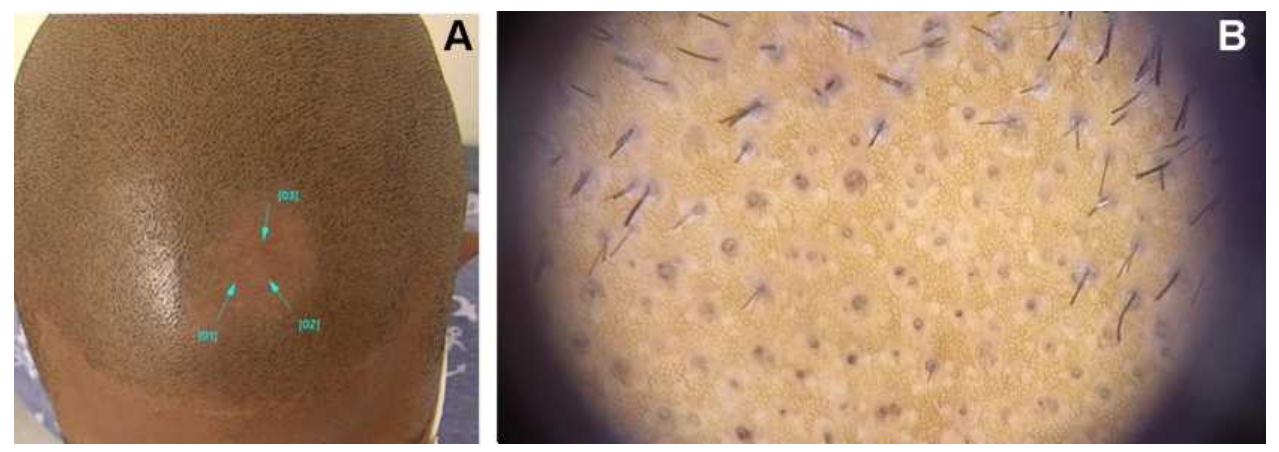

Figure 2 (A and B) Trichoscopy points to keratotic plugs in this case of early discoid lupus erythematosus (DLE) that has been previously diagnosed and treated as alopecia areata (FotoFinder Systems, x40).

characterized by deep inflammatory infiltrate, increased catagen/telogen count and pigmented casts (Figure 3), and lichen planopilaris (LPP)-like pattern (18\%) that shows the inflammatory infiltrate and perifollicular fibrosis at the upper follicular level. ${ }^{14}$ Direct immunofluorescence (DIF) of lesional skin is positive for a lupus band in $60 \%$ to $80 \%$ of cases. $2,5,11$

\section{Non-Scarring Alopecia in SLE}

Non-scarring alopecia in SLE is frequently referred to in the literature as a LE non-specific cutaneous finding. ${ }^{2,7}$ However, recent studies have shown that non-scarring alopecia in SLE often demonstrates LE-specific changes on histology and DIF. ${ }^{4,5,8}$ While it has been suggested that non-scarring alopecia in SLE may represent early DLE, 5,8 the authors of the current review regard non-scarring alopecia in SLE as a distinct, independent entity based on its

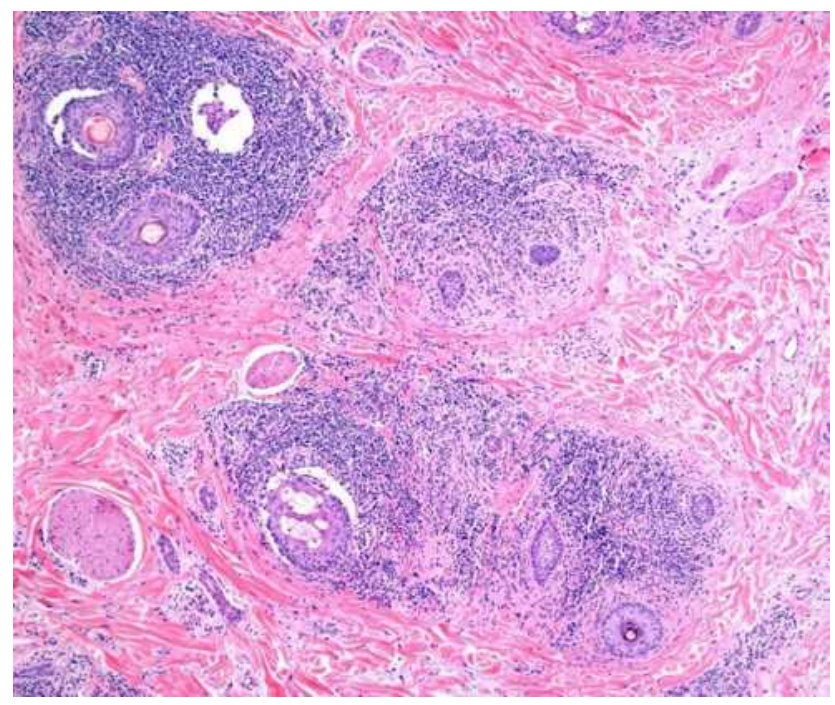

Figure 3 Histologic image of the alopecia areata (AA) subtype of discoid lupus erythematosus (DLE) shows significant interface dermatitis involving the follicular epithelium and increased telogen count (hematoxylin and eosin, $x \mid 0$ ). clinical course, trichoscopic, and histologic features. Histological changes in non-scarring alopecia of SLE are more comparable to acute CLE than DLE. ${ }^{21}$ Additionally, non-scarring alopecia in SLE manifests abruptly and predominantly in patients with severe, uncontrolled SLE, and it has been demonstrated to correlate with underlying disease activity prevalence of proteinuria $\left(>1 \mathrm{~g} / \mathrm{d}^{8}\right)$. It has a good prognosis and usually resolves when systemic disease is controlled. . $^{2,5,8,9,21,22}$ In a recent study, the presence of certain trichoscopic features in patients with SLE was found to correlate with disease severity; patients with hair shaft changes (including decreased number of hairs, decreased diameter, and hypopigmentation) had more active systemic disease, as determined by significantly higher mean Systemic Lupus Erythematosus Disease Activity Index (SLEDAI) scores, than those without these trichoscopic features. ${ }^{23}$

Non-scarring alopecia of SLE may assume a diffuse, patchy, or "lupus hair" pattern. ${ }^{5}$ It therefore must be distinguished from telogen effluvium or AA which may also occur concomitantly with SLE. The patchy pattern may be mistakenly diagnosed clinically as AA. ${ }^{2,22}$ Erythema and patches of reduced hair density (as opposed to patches of complete hair loss) may help distinguish LE patchy alopecia from AA. ${ }^{2,5,22}$ Additionally, trichocoscopic findings in SLE have been described that may aid in the diagnosis and include: hair shaft changes (decrease in number/diameter and hypopigmentation), black dots, brown scattered pigmentation, blue-grey pigmentation, and prominent and thick arborizing blood vessels. $4,5,22$

Lupus hair refers to alopecia and dry/coarse appearance of the frontal hairline due to increased hair fragility, a striking sign that can be seen in patients with SLE. ${ }^{2,5,6,24}$ Similar to other patterns of non-scarring alopecia in SLE, lupus hair is thought to result from severe inflammation 
promoting a catabolic state and negative nitrogen balance which negatively affects hair growth. ${ }^{2}$

\section{SCLE}

Though SCLE rarely involves the scalp, there have been reports of SCLE causing non-scarring alopecia., ${ }^{5,25}$ SCLE is characterized clinically by annular or psoriasiform plaques with psoriasiform hyperplasia and perivascular inflammatory infiltrate on histopathology; a positive lupus band on DIF may help distinguish SCLE from psoriasis. ${ }^{5,25}$

\section{Tumid LE}

Tumid LE is a subtype of chronic CLE and has been reported in rare cases to affect the scalp resulting in nonscarring, patchy hair loss. ${ }^{5,26,27}$ Clinically tumid LE is characterized by erythematous, indurated papules and plaques with no surface change, and histopathological evaluation shows no interface dermatitis but significant mucin infiltration in the deep dermis. $5,26,27$

\section{LE Panniculitis/Profundus}

LEP, a rare lesion within the spectrum of chronic CLE, is capable of producing both non-scarring and scarring alopecia when it affects the scalp. ${ }^{20,28-30}$ When the inflammation is confined to the lower layers of the skin and affects only the lower portion of the hair follicle (the follicular bulbs), the stem cells of the hair follicle are preserved; therefore, the hair loss is non-scarring. ${ }^{20,30}$ Although rare in LEP, if the inflammation affects the dermis surrounding the bulge of the follicle, permanent loss of the hair follicle and irreversible alopecia may ensue. $^{20,29,30}$

Clinically, LEP of the scalp may present as tender, slightly erythematous patches of hair loss, sometimes with overlying ulceration ${ }^{20,28-30}$ (Figure 4). Trichoscopic features including large yellow dots, black dots, short vellus hairs, thick arborizing vessels, and diffuse erythema of the interfollicular areas have been described. ${ }^{21}$ Histopathological evaluation shows predominantly lymphocytic infiltration of the subcutaneous lobules (lobular panniculitis) and deep dermis, mucinosis, and hyalinization of the fat. ${ }^{28,29}$ LEP has been reported to cause alopecia along Blaschko's lines in East Asian men and that subtype is termed Linear and annular lupus panniculitis of the scalp (LALPS). ${ }^{28,30}$ It bears a better prognosis and is less frequently associated with SLE.

\section{LE Non-Specific Alopecia}

Several other non-scarring types of alopecia may occur in patients with LE most likely as a coincidental finding ${ }^{5,8}$ since histology fails to show LE-specific features. ${ }^{5}$

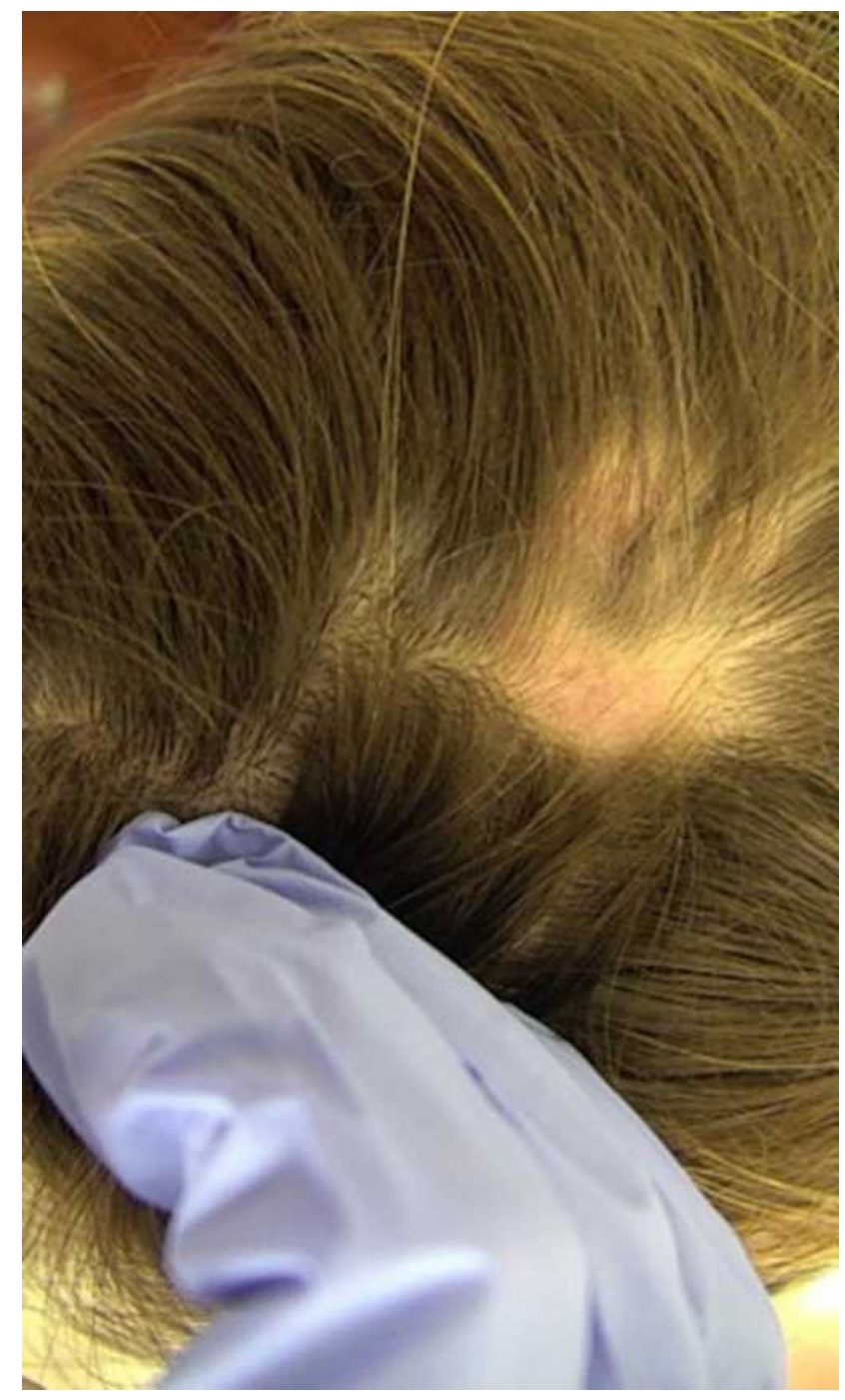

Figure 4 Clinical image demonstrates alopecia in lupus panniculitis of the scalp with notable erythema and lack of keratotic plugs or scale.

\section{Telogen Effluvium (TE)}

TE may complicate SLE as a result of severe inflammation, anemia, physical/mental stress, or medications. ${ }^{2,5,20}$ Pro-inflammatory cytokines and severe catabolic effects can negatively affect the hair growth cycle, causing diffuse hair shedding and/or thinning. ${ }^{2,5}$ A hair pull test, performed by randomly grasping 50-60 hairs, can aide in the diagnosis of TE when more than 5-6 telogen hairs are pulled. $^{24}$

As previously mentioned, diffuse alopecia occurring during acute exacerbations of SLE is a frequent occurrence. ${ }^{5,6}$ The etiology of diffuse alopecia in patients with SLE has been largely attributed to $\mathrm{TE} ;^{4,7}$ however, histopathological examination is often not performed. Specific LE-changes on histology may differentiate TE 
from diffuse non-scarring hair loss of SLE. ${ }^{8}$ Additionally, TE ensues months after a stressful insult or trigger, whereas LE-specific diffuse alopecia occurs concomitantly with disease flares. ${ }^{5}$ Nevertheless, a clear distinction may not always be possible, and in our experience, the dermatological treatment with topical steroids with/without topical minoxidil renders significant improvement in either type.

\section{Alopecia Areata (AA)}

It has been suggested that there is a higher incidence of AA in patients with SLE than among general dermatologic patients, perhaps due to a common autoimmune diathesis. ${ }^{6,7,14}$ However, patchy hair loss of SLE may also have been misdiagnosed as AA. Deep dermal mucin in a biopsy of non-scarring alopecia may be a clue to underlying SLE, ${ }^{2}$ as this is not a feature of typical biopsies of AA. ${ }^{31}$ This diagnostic distinction is important as the prognosis of AA is unpredictable, whereas non-scarring alopecia of SLE should improve with good control of systemic disease. ${ }^{5}$

\section{Anagen Effluvium (AE)}

Certain drugs (namely cytotoxic agents and antimetabolites) used in LE and occasionally severe systemic inflammation can cause the rapidly dividing matrix cells of anagen hair follicles to suddenly and temporarily stop dividing, resulting in dystrophic AE. ${ }^{2,5,24}$ Clinically this presents as scalp/body hair loss and narrowed segments of the hair shaft (Pohl-Pinkus constriction) resulting in hair shaft breakage. ${ }^{2,5,24} \mathrm{~A}$ pull test will be positive for anagen and telogen hairs. ${ }^{5}$ AE occurs as early as one week after the triggering insult. ${ }^{5}$

\section{Management of LE-Specific Alopecia}

Data regarding the management of lupus alopecia are sparse and limited to case reports. Thus, many studies included in the current review report the efficacy of treatments on CLE as a broader entity. Systematic reviews have noted a paucity of high-quality evidence for the management of CLE as well. ${ }^{32,33}$

The Cutaneous Lupus Erythematosus Disease Area and Severity Index (CLASI) is often utilized in the literature to assess the clinical response of CLE. ${ }^{34}$ The CLASI score can be separated into an "activity" and a "damage" score. The activity score accounts for non-scarring alopecia in addition to erythema, scale/hypertrophy, and mucous membrane involvement. The damage score comprises dyspigmentation, scarring, atrophy, and panniculitis: features that may be seen in association with scarring alopecia.

\section{General Principles}

For patients with non-scarring alopecia in SLE (diffuse, patchy, and lupus hair), management is aimed at controlling SLE activity with expected subsequent hair regrowth. Adjuvant topical treatment with high potency steroids, such as clobetasol $0.05 \%$, with or without topical minoxidil can expedite recovery, which usually occurs in 3 months (Figure 5). Management of SLE other than firstline therapy with oral antimalarials ${ }^{32}$ is beyond the scope of this review.

Chronic CLE can cause primary cicatricial alopecia, which is generally considered to be permanent. ${ }^{13,35}$ Therefore, prompt treatment is crucial to target early inflammation and prevent irreversible damage. ${ }^{12,13,30,35}$ The goal of treatment for any primary cicatricial alopecia is to prevent progression of hair loss, and regrowth should not be expected once scarring has ensued. ${ }^{11}$

Treatments for LE alopecia are summarized in Table 1. According to recent guidelines by the European Dermatology Forum (EDF) and the European Academy of Dermatology and Venerology (EADV), current first-line therapies for CLE include topical corticosteroids for localized disease and systemic treatment with antimalarials for severe/widespread disease. ${ }^{36}$ Systemic corticosteroids are often used as a bridging therapy and recommended as firstline treatment in highly active, severe CLE with high-risk of scarring, ${ }^{36}$ which includes DLE-associated alopecia (Figure 6). In our experience oral dexamethasone as a mini-pulse of dose $0.1 \mathrm{mg} / \mathrm{kg}$ on two consecutive days of the week is a well-tolerated alternative to oral prednisone and has negligible mineralocorticoid effects.

Second and third-line systemic treatments for CLE include methotrexate, retinoids, dapsone, mycophenolate mofetil (MMF), and mycophenolate acid (MPA). ${ }^{36}$

\section{Lifestyle Measures}

Sun-exposure is known to exacerbate and precipitate CLE, 2,32,37 and studies have demonstrated decreased interferon-mediated inflammation in biopsies of skin protected by sunscreen. ${ }^{37,38}$ Thus, photoprotection and sun avoidance are important preventative measures. ${ }^{2,11,32}$ Higher sun protection factor (SPF 60 or greater), broad-spectrum UVA/UVB coverage, and physical protection are recommended. ${ }^{37}$ 


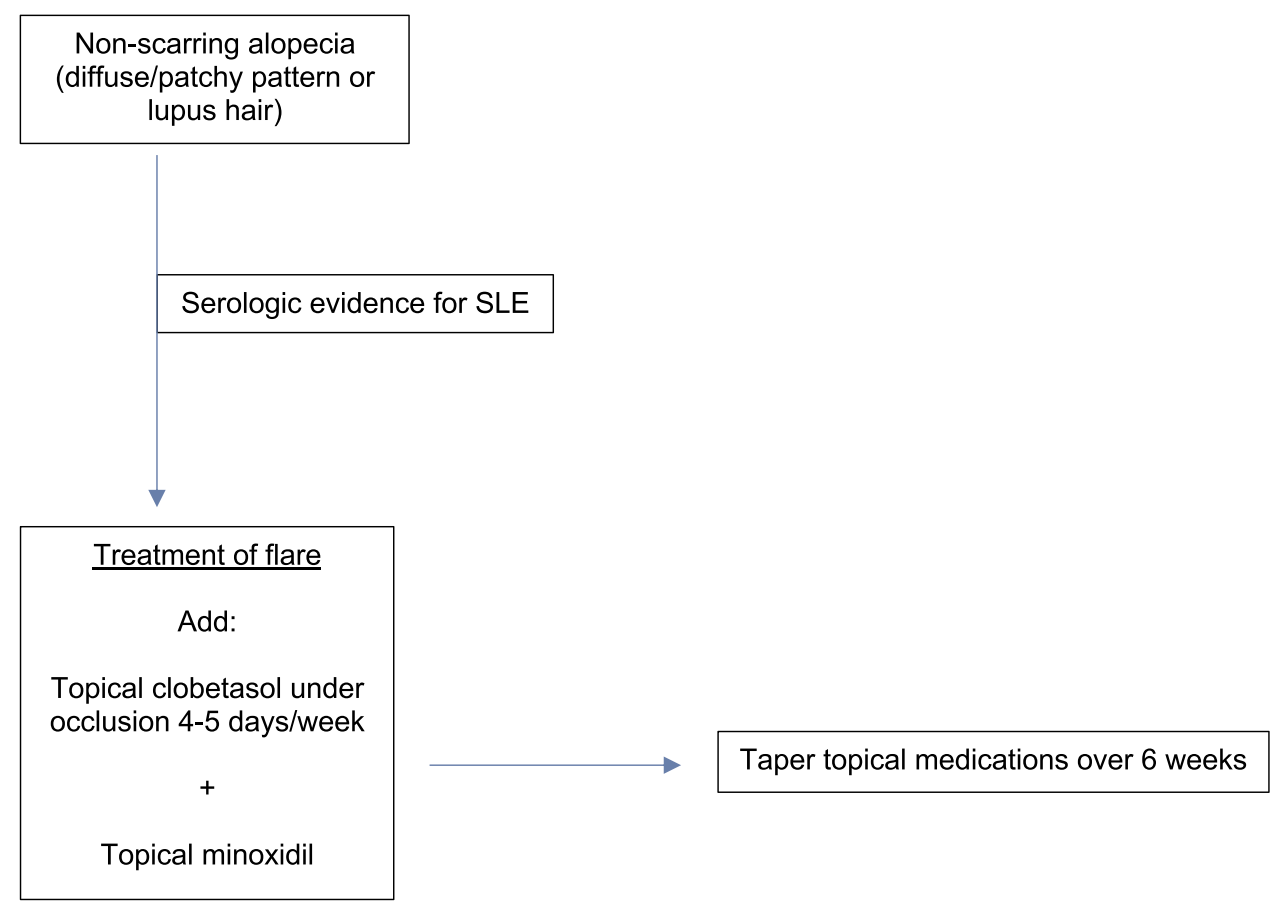

Figure 5 Algorithm describes an approach to treatment of discoid lupus erythematosus (DLE) on the scalp. Abbreviations: SLE, systemic lupus erythematosus; IL, intralesional; IVIG, intravenous immunoglobulin.

Smoking tobacco has been found to be more prevalent among patients with $\mathrm{DLE}^{39}$ and has been associated with more severe manifestations of $\mathrm{CLE}^{40}$ as well as decreased

Table I Therapies for LE Alopecia

\begin{tabular}{|c|c|}
\hline Topical therapies & $\begin{array}{l}\text { Corticosteroids* (including intralesional) } \\
\text { Calcineurin inhibitors } \\
\text { R-salbutamol } \\
\text { Retinoids }\end{array}$ \\
\hline Systemic therapies & $\begin{array}{l}\text { Anti-malarials } \pm \text { corticosteroids* } \\
\text { Retinoids } \\
\text { MTX } \\
\text { Dapsone } \\
\text { MMF/MPA } \\
\text { Thalidomide/lenalidomide } \\
\text { FAEs } \\
\text { Apremilast } \\
\text { Azathioprine } \\
\text { Cyclosporine } \\
\text { IVIG } \\
\text { JAK inhibitors } \\
\text { Biologics }\end{array}$ \\
\hline Physical modalities & $\begin{array}{l}\text { Light/laser therapy } \\
\text { Hair transplantation }\end{array}$ \\
\hline
\end{tabular}

Note: Bold asterisk $(*)$ denotes first-line therapies.

Abbreviations: MTX, methotrexate; MMF, mycophenolate mofetil; MPA, mycophenolate acid; FAEs, fumaric acid esters; IVIG, intravenous immunoglobulin; JAK, janus kinase. efficacy of treatment. ${ }^{41}$ Though the pathomechanism of smoking on the natural history LE is not fully understood, smoking cessation is strongly recommended. ${ }^{32,37,42,43}$

\section{Current First-Line Therapies: Corticosteroids and Antimalarials}

In concordance with EDF and EADV guidelines, topical/ IL corticosteroids and oral antimalarials are widely recommended as first-line therapies for CLE, ${ }^{11,37,42,44-49}$ though approximately $30-40 \%$ of CLE cases will remain refractory to standard first-line treatments. ${ }^{50}$ Data supports the use of high-potency topical corticosteroids over lower-potency formulations. ${ }^{2,11,13,33,37}$ Using highpotency steroids under occlusion can improve efficacy. A stepwise approach is often employed beginning with topical therapies and subsequently introducing oral antimalarials. ${ }^{12,37}$ However, an aggressive multi-modal approach is often necessary to prevent irreversible alopecia in patients with chronic CLE ${ }^{12,30,43,51}$ including oral corticosteroids as bridging therapy. ${ }^{11,12,37,51}$

Long-term systemic therapy with antimalarials is indicated for non-scarring alopecia in SLE, and topical/intralesional (IL) steroids may hasten hair regrowth. ${ }^{2}$

Hydroxychloroquine (HCQ) has demonstrated efficacy in treating CLE/DLE and is traditionally used as a first-line 


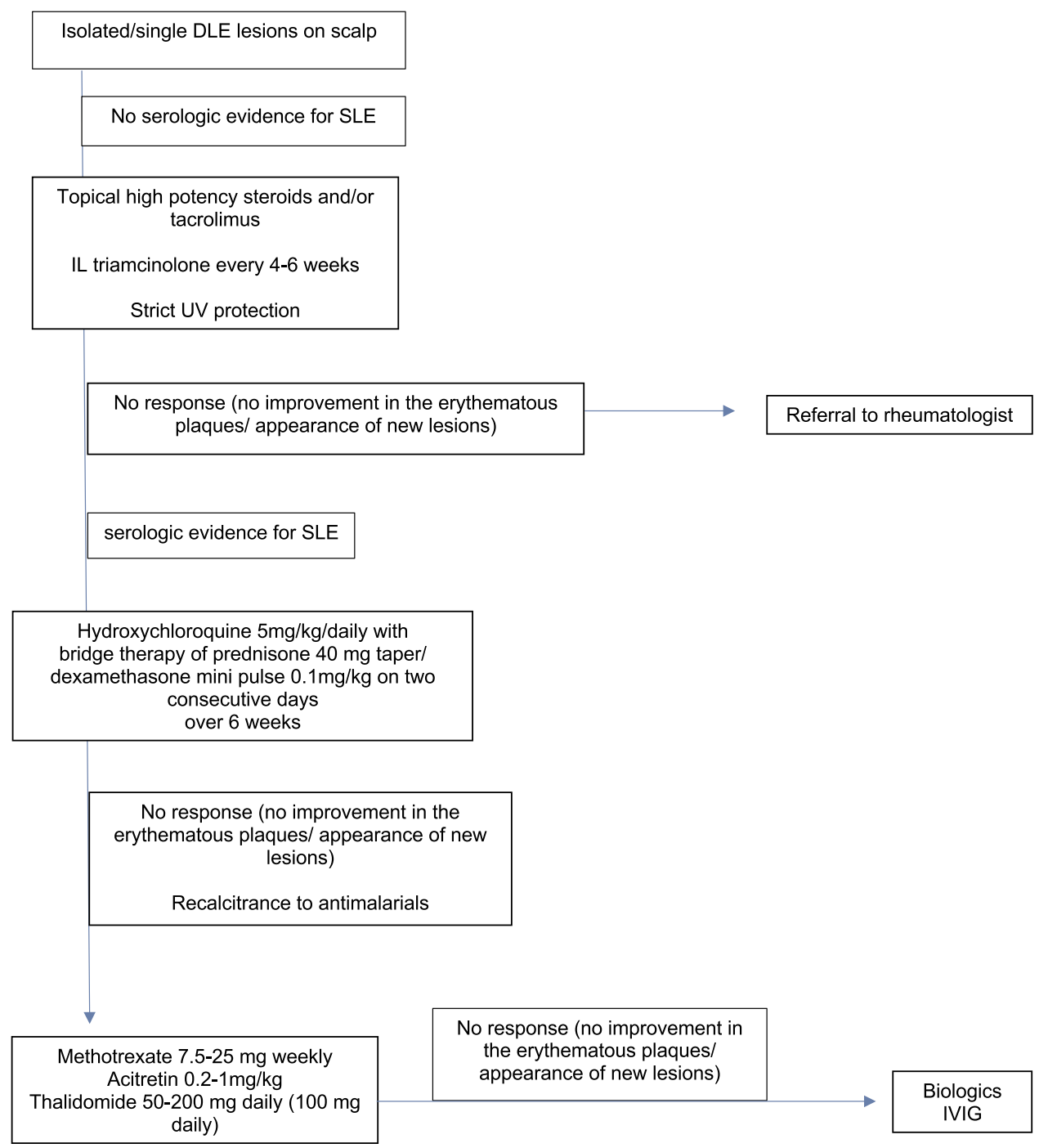

Figure 6 Algorithm describes an approach to treatment of non-scarring alopecia in systemic lupus erythematosus (SLE).

antimalarial. ${ }^{11,32,33,52}$ HCQ is the hydroxyl derivative of chloroquine, and both are antimalarial agents that have proven useful in the treatment of autoimmune diseases, including SLE and rheumatoid arthritis. ${ }^{53}$ Unlike other immunomodulatory therapies, HCQ treatment has actually been associated with a reduction in infections. ${ }^{53}$ Though few hypotheses exist, the precise mechanism of action of HCQ remains elusive. ${ }^{53}$ Early HCQ treatment may delay the occurrence of cutaneous damage in patients with SLE. ${ }^{54}$ However, in one study, less than $50 \%$ of patients with DLE maintained long-term clinical response to hydroxychloroquine. ${ }^{55}$ Combination therapy with HCQ and quinacrine may be more effective than HCQ monotherapy, particularly in patients who fail the latter. ${ }^{56} \mathrm{HCQ}$ can also be replaced by chloroquine. ${ }^{11}$
The efficacy of HCQ in treating individual cutaneous manifestations, including alopecia, is not well reported. In case reports, treatment with HCQ as monotherapy or in combination with other treatments resulted in improvement in alopecia secondary to variants of CLE, including DLE, LEP, and tumid LE. ${ }^{12,20,28,30,44,57-59}$ It is important to note that HCQ above a dose regimen of $5 \mathrm{mg} / \mathrm{kg}$ is associated with significant ocular toxicity and should be avoided. ${ }^{60}$

\section{Topical Therapies Topical Calcineurin Inhibitors (TCls)}

Randomized comparative trials and other studies have demonstrated the efficacy of TCIs (tacrolimus and pimecrolimus) in the treatment of CLE, ${ }^{32,61,62}$ though clinical 
improvement was not always sustained with longer periods of follow-up. ${ }^{63}$ TCIs are considered first- or secondline agents for $\operatorname{CLE}^{11,36,37,49}$ and may exhibit comparable efficacy to topical corticosteroids ${ }^{62}$ with an improved side effect profile. ${ }^{13,32,37,62,63}$ Case reports have documented the success of topical tacrolimus in promoting significant hair regrowth in 4 patients with recalcitrant alopecia secondary to DLE, both as monotherapy (using $0.1 \%$ ointment) ${ }^{64}$ and as an adjunct to oral antimalarial (using compounded $0.3 \%$ lotion). ${ }^{13}$

\section{R-Salbutamol}

$\mathrm{R}$-salbutamol is a beta-2-adrenergic receptor agonist that has shown efficacy as a topical formulation in the treatment of CLE. ${ }^{32,43,65}$ A randomized controlled trial (RCT) involving 37 patients with DLE found statistically significant improvement in scaling/hypertrophy, induration, patient global assessment, and lesional size when treated with R-salbutamol topically. ${ }^{66}$ A prospective study that examined the use of topical R-salbutamol on patients with SCLE and treatment-resistant DLE found improvement in both subtypes of CLE but a better response in SCLE. ${ }^{67}$ However, topical R-salbutamol is not currently commercially available, ${ }^{43}$ and new data have not been published since $2009 .^{65}$

\section{Retinoids}

Topical retinoids (tazarotene and tocoretinate) have also been used to successfully treat refractory DLE lesions in case reports. ${ }^{68,69}$ Tocoretinate (a synthetic esterified compound of tocopherol and retinoic acid) improved erosions and erythema due to DLE as well as signs of damage (dyspigmentation and atrophy) in a case series. ${ }^{69}$

\section{Systemic Therapies}

\section{Retinoids}

Systemic retinoids are considered second-line treatment options for CLE, ${ }^{36,46,47,68,70}$ and a RCT suggested that acitretin may be equally as effective as HCQ in improving/clearing erythema, infiltration, and scaling of CLE lesions, ${ }^{33,71}$ though more frequent and severe adverse events occurred with acitretin. In a more recent case series, 3 patients with different forms of CLE (including DLE and SCLE) refractory to various other topical and systemic agents demonstrated excellent clinical improvement with alitretinoin and suffered minimal side effects. ${ }^{47}$ Oral isotretinoin has also been effective in refractory CLE, including ACLE, SCLE, and DLE. ${ }^{11,70,72,73}$ An important consideration is that systemic retinoids are associated with reversible alopecia. ${ }^{2}$

\section{Methotrexate (MTX)}

In a retrospective study of 43 patients with CLE, low-dose MTX, as both monotherapy and adjunctive therapy, resulted in significant improvement in activity of cutaneous lesions in $98 \%$ of patients. Alopecia was not explicitly considered in the Cutaneous Lupus Activation Index (CLAI) which was used to assess disease activity and clinical response. ${ }^{3}$ In fact, of non-antimalarial treatments, thalidomide and methotrexate were the most effective options in CLE recalcitrant to antimalarials, according to a recent retrospective study. ${ }^{74}$ These data are supported by a previous retrospective analysis that demonstrated clinical improvement in approximately $83 \%$ of patients with refractory CLE (including DLE, SCLE, LEP) and complete response in 50\% with low-dose MTX. In a randomized comparative trial, low-dose MTX was found to be equally effective as chloroquine in clearance of skin rash associated with SLE. ${ }^{75}$ MTX is associated with severe toxicities, namely bone marrow suppression and hepatotoxicity, which occasionally required discontinuation of treatment in these studies. ${ }^{3,75}$

\section{Dapsone}

In a retrospective analysis of 34 patients with CLE, dapsone with or without antimalarials resulted in clinical improvement in more than $58 \%$ of patients and complete remission in approximately $17 \%{ }^{76}$ In a case report, dapsone resulted in rapid clinical improvement of recalcitrant scarring alopecia due to chronic CLE after a biopsy demonstrated neutrophils in the inflammatory infiltrate. ${ }^{77}$ This case illustrates the utility of histology-guided treatment, a recommended principle for the management of cicatricial alopecia. ${ }^{11}$

\section{Mycophenolate Mofetil (MMF) and Mycophenolate Acid (MPA)}

In non-comparative studies and case series, MMF or MPA resulted in clinical improvement in $90-100 \%$ of patients with variants of CLE. ${ }^{78-80}$ However, in another study, 5 out of 7 patients with therapy-resistant cutaneous manifestations of SLE achieved no clinical improvement with MMF. ${ }^{81}$

\section{Thalidomide and Lenalidomide}

Thalidomide, a glutamic acid derivative with anti-tumor and immunomodulatory properties, and its synthetic 
analog lenalidomide have demonstrated success in treating refractory CLE. ${ }^{32,42,45,50,82}$

A meta-analysis found an overall response rate of $90 \%$ in 548 chronic CLE patients with thalidomide treatment, with similar efficacy among severe CLE subtypes. ${ }^{42}$ In observational studies and case reports, thalidomide therapy has resulted in a significant and rapid clinical improvement of recalcitrant active CLE lesions in at least $80-90 \%$ of patients. ${ }^{50,82,83}$ Thalidomide has also been reported to significantly improve alopecia associated with DLE in a pediatric patient. ${ }^{59}$ However, its use is limited by severe side effects, including teratogenicity, peripheral neuropathy, and thrombosis, as well as frequent relapses after withdrawal of therapy. ${ }^{42,50,82-84}$

In several non-comparative trials and observational studies, lenalidomide proved efficacious in treating refractory CLE, without inducing or worsening peripheral neuropathy. ${ }^{45,50,84,85} 77-100 \%$ of patients in different studies achieved clinical response, ${ }^{45,50,84,85}$ and at least $43-86 \%$ achieved complete response as determined by a CLASI activity score of $0 .{ }^{45,50,85}$ Lenalidomide was found to be safe and effective in the treatment of refractory cutaneous manifestations of SLE in pediatric patients; in a retrospective study of 10 adolescents, $100 \%$ of patients achieved complete or near complete resolution at 6 months of treatment, including hair regrowth in patients with extensive alopecia. ${ }^{86}$ Similar to thalidomide, however, lenalidomide was associated occasionally with arterial thromboses ${ }^{85}$ and frequent relapse upon dose reduction or discontinuation. ${ }^{50,85}$

\section{Fumaric Acid Esters (FAEs)}

FAEs are approved for the treatment of psoriasis and multiple sclerosis, and they are thought to exert immunomodulatory activity through inhibition of the transcription factor nuclear factor (NF)-kB and T-cell mediated inflammation. ${ }^{1,65,87}$ In a Phase II non-comparative trial, treatment with FAEs resulted in significant decrease in mean revised-CLASI activity scores in patients with recalcitrant CLE (DLE and SCLE). ${ }^{1}$ Reductions in mean R-CLASI damage scores were noted, though they were not statistically significant. ${ }^{1}$ Side effects included abdominal pain and headaches; no severe adverse events occurred. ${ }^{1}$ Recent case reports have also documented the efficacy of FAEs as an adjuvant to other systemic therapies in treating severe, recalcitrant cutaneous manifestations of SLE, with favorable tolerability. ${ }^{87,88}$

\section{Apremilast}

In a phase II open-label pilot trial, treatment with apremilast as monotherapy resulted in significant decline in both CLASI activity and damage scores in patients with DLE.

Adverse events were mild and transient. ${ }^{89}$

Apremilast is a phosphodiesterase-4 inhibitor with immunomodulatory activity, particularly with regard to Th- 1 and Th-17 mediated activity. ${ }^{65}$ Though data are currently very limited, apremilast may be a viable and safe therapeutic option in CLE. ${ }^{32,65,89}$

\section{Azathioprine}

Azathioprine has been reported to be effective as adjuvant therapy in difficult cases of CLE, including DLE and SCLE. It is also associated with occasionally severe side effects including myelosuppression and malignancy, among others. ${ }^{11,32,65,90}$ It is not recommended for CLE according to the European guidelines in the absence of associated SLE. ${ }^{36,43}$

\section{Cyclosporine}

Very scarce documentation exists on the use of cyclosporine to treat CLE. ${ }^{11,32}$ In two cases of refractory SCLE, cyclosporine A in conjunction with MTX was effective, ${ }^{46}$ but in other cases of chronic CLE, cyclosporine has been ineffective. $^{91}$

\section{Intravenous Immunoglobulin (IVIG)}

Few heterogenous studies and case reports have documented the efficacy of IVIG in the treatment of CLE, including DLE and SCLE, though some conflicting data exist. ${ }^{32,49,65,92}$ A recent proof-of-concept study reported overall clinical improvement with reduction in CLASI-A scores, low rates of relapse, and no serious adverse effects in patients with recalcitrant CLE when treated with IVIG as monotherapy. ${ }^{93}$

\section{Janus Kinase (JAK) Inhibitors}

JAK inhibitors are being studied for their efficacy in many autoimmune and inflammatory disease processes, including SLE. ${ }^{9}$ Various JAK inhibitors including tofacitinib, ruxolitinib, and baricitinib have demonstrated promising results in the treatment of AA. ${ }^{9}$

Baricitinib is an inhibitor of JAK 1 and 2, approved for the treatment of rheumatoid arthritis. In a phase II study, baricitinib significantly improved the severity of rash and arthritis in patients with active SLE refractory to standard therapy. ${ }^{94}$ In a recent case report, introduction of baricitinib resulted in significant improvement in diffuse 
non-scarring alopecia in a patient with SLE that was refractory to several lines of therapy. ${ }^{9}$ Given limited data on the use of JAK inhibitors in SLE and SLE alopecia, authors are cautiously optimistic. ${ }^{9}$ Notably, JAK inhibitors are occasionally associated with severe adverse effects, including infection and thrombosis. ${ }^{95}$

\section{Belimumab}

Belimumab is the only biological therapy approved by the FDA to treat SLE; $;^{43,96}$ however, data to support its efficacy in CLE are more limited. ${ }^{32,43}$ Belimumab targets soluble B-lymphocyte stimulator (BLyS), which was found to be significantly more expressed in lesional biopsies of all CLE subtypes compared to controls. ${ }^{97}$ In a large, multicentric retrospective analysis of 11 prospective cohorts, median CLASI-activity scores significantly decreased overtime with belimumab treatment. ${ }^{96}$ A post hoc analysis of combined data from two Phase III clinical trials comparing belimumab to placebo found that significantly more patients in the treatment group had improvement in their mucocutaneous manifestations of SLE. ${ }^{98}$ A recent study aimed to evaluate efficacy of belimumab specifically on refractory, severe CLE and found that belimumab therapy resulted in dramatic improvement in CLASI-activity scores (and no worsening of CLASI damage scores) in a small cohort of patients. ${ }^{99}$ Additionally, belimumab is associated with a very good safety profile, with low rates of infusion reactions as well as other severe adverse events. ${ }^{96}$

\section{Rituximab}

Phase III trials investigating the efficacy of rituximab in SLE did not meet their endpoint. ${ }^{43}$ However, some observational studies have supported its efficacy in improving CLE, particularly ACLE. ${ }^{32,43,65}$ A retrospective cohort study analyzed the efficacy of rituximab in SLE patients with several subtypes of CLE, including ACLE, SCLE, CCLE, and non-specific LE (NSLE). NSLE included alopecia. Rituximab therapy (with or without cyclophosphamide) resulted in clinical improvement with all subtypes, but more so in patients with ACLE and NSLE. ${ }^{100}$

Another prospective study involving SLE patients receiving rituximab therapy found that patients with ACLE responded favorably whereas those with chronic CLE did not respond; rather, new chronic CLE lesions emerged in some patients while on rituximab. ${ }^{101}$ Authors of this report surmise that inflammation in CLE is B-cell independent. ${ }^{101}$

\section{Ustekinumab}

In a recent phase II RCT, ustekinumab in addition to standard-of-care therapy was more effective than placebo in treating SLE and resulted in significant improvement in CLASI-activity scores. ${ }^{102}$ In case reports, ustekinumab has been effective in treating severe and recalcitrant CLE, including ACLE, SCLE, and DLE. ${ }^{103-106}$ Ustekinumab inhibits the p40 subunit shared by the cytokines IL-12 and IL-23, and IL-23 plays an important role in the expansion and survival of pathogenic IL-17-producing cells. ${ }^{102,103}$ These cytokines have been found to be elevated in the serum of patients with SLE, ${ }^{103}$ and IL-17A has been found to be significantly elevated in the skin of patients with CLE. ${ }^{107}$ Ustekinumab has a very favorable safety profile and may play a role in the treatment of CLE, pending further studies. ${ }^{43,65,102}$

\section{Anti-Tumor Necrosis Factor (TNF)-Alpha Biologics}

Anti-TNF-alpha inhibitors, though theoretically could be efficacious in treating CLE, have not been effective in observational studies. ${ }^{11,65}$ On the contrary, available data have raised concerns that these drugs may actually trigger and/or exacerbate LE. ${ }^{11,65}$ However, a recent retrospective analysis found that only $1 / 20$ patients with concomitant LE and psoriatic disease experienced a clinical flare of lupus while on treatment, translating to an incidence of clinical flares of $0.92 \%$ events per patient-year. ${ }^{106}$

\section{Other Biologics}

Limited data suggest the potential utility of other biological agents in the treatment of CLE. ${ }^{32,43,65}$ BIIBB059 is a monoclonal antibody that targets blood dendritic cell antigen 2, a plasmacytoid dendritic cell-specific receptor. In a RCT involving 12 patients with SLE, single doses of BII059 resulted in decreased CLASI-activity scores and reduced inflammatory infiltrates in skin lesions. ${ }^{108} \mathrm{~A}$ post hoc analysis on data from an $\mathrm{RCT}^{109}$ that demonstrated the efficacy of anifrolumab (anti-interferon-alpha receptor monoclonal antibody) in SLE noted statistically significant improvements in rash versus placebo. ${ }^{110}$ Similarly, a phase II RCT that investigated the efficacy of another antiinterferon-alpha monoclonal antibody, Sifalimumab, noted improvements in CLASI scores in the treated group compared to placebo. ${ }^{111}$

Interferon-gamma is implicated in the pathogenesis of DLE; however, a Phase I RCT showed no clinical benefit in patients with DLE when treated with AMG 811, an antiinterferon-gamma antibody. ${ }^{112}$ 


\section{Physical Modalities \\ Laser and Light Therapy}

Laser and light therapies, including pulse-dye laser (PDL) and intense pulsed light (IPL) among others, have demonstrated success in treating both the activity and damage of DLE lesions, ${ }^{48,113-118}$ sometimes with confirmed histologic improvement and reduction of inflammation. ${ }^{117,118}$ Most data support the efficacy of PDL with a wavelength of $585-595 .^{32,37}$ A recent RCT aimed to investigate the efficacy of PDL $(595 \mathrm{~nm})$ in the treatment of DLE and found that lesions treated with PDL demonstrated significant reductions in erythema, texture, and physician global assessment compared to controls. ${ }^{117}$ Improvement in modified CLASI scores was not significant. Side effects in treating CLE with PDL are often minimal and included dyspigmentation and transient pain: scarring was rare. ${ }^{32,113}$ Despite limited data suggesting the efficacy of light/laser therapies in CLE, European guidelines ${ }^{36}$ recommend against the use of UV light and laser treatments in patients with CLE due to photosensitivity and risk of koebernization. ${ }^{36,65}$

\section{Hair Transplantation}

A recent systematic review noted the scarcity of documentation on hair transplantation in patients with scarring alopecia, particularly in patients with chronic CLE. ${ }^{119}$ An old study noted positive results for 8 patients with DLE who underwent punch graft transplants (an average of $72 \%$ graft survival). ${ }^{120}$ However, graft destruction has been reported in patients with other forms of primary cicatricial alopecia. ${ }^{11,119}$ Cutaneous LE and any underlying SLE if present must be controlled before considering hair transplantation surgery ${ }^{2,11,119}$ due to risk of koebnerization. ${ }^{2}$ A general recommendation, though not well substantiated by data, is that underlying disease should be inactive for at least two years prior to surgery. ${ }^{11,119}$

\section{Conclusion}

Data regarding the specific effect of treatment regimens on the reversal of LE alopecia are severely lacking. Though often not reported, it may be inferred that the treatment of SLE will also improve associated non-scarring alopecia.

Presence of chronic CLE often warrants early, aggressive, multi-modal intervention due to the risk of scarring resulting in irreversible hair loss. Close collaboration with a rheumatologist should be implemented in the care of patients with LE. Currently, topical/IL corticosteroids and oral antimalarials are the mainstay of therapy for CLE.
A recent systematic review of RCTs highlighted the lack of evidence for many drugs other than topical steroids, hydroxychloroquine, and acitretin in the treatment of DLE. ${ }^{33}$

TCI's have demonstrated efficacy in treating CLE and LE alopecia specifically, and other topical treatment options include retinoids and R-salbutamol. Second-line and third-line systemic therapies for CLE include methotrexate (MTX), retinoids, dapsone, mycophenolate mofetil (MMF)/mycophenolate acid (MPA), and thalidomide. ${ }^{36}$ Systemic therapy with lenalidomide, FAEs, azathioprine, apremilast, IVIG, and biologicals (including ustekinumab, rituximab and belimumab) have also been efficacious in individual reports and small series. Oral and topical minoxidil may be used adjuvant treatments to support hair growth. ${ }^{11,35}$

\section{Disclosure}

The authors report no conflicts of interest in this work.

\section{References}

1. Kuhn A, Landmann A, Patsinakidis N, et al. Fumaric acid ester treatment in cutaneous lupus erythematosus (CLE): a prospective, open-label, phase II pilot study. Lupus. 2016;25(12):1357-1364. doi: $10.1177 / 0961203316644335$

2. Trüeb RM. Involvement of scalp and nails in lupus erythematosus. Lupus. 2010;19(9):1078-1086. doi:10.1177/ 0961203310373938

3. Wenzel J, Brähler S, Bauer R, Bieber T, Tüting T. Efficacy and safety of methotrexate in recalcitrant cutaneous lupus erythematosus: results of a retrospective study in 43 patients. $\mathrm{Br}$ $J \quad$ Dermatol. 2005;153(1):157-162. doi:10.1111/j.13652133.2005.06552.x

4. Gong Y, Ye Y, Zhao Y, et al. Severe diffuse non-scarring hair loss in systemic lupus erythematosus - clinical and histopathological analysis of four cases. J Eur Acad Dermatol Venereol. 2013;27 (5):651-654. doi:10.1111/j.1468-3083.2011.04388.x

5. Concha JSS, Werth VP. Alopecias in lupus erythematosus. Lupus Sci Med. 2018;5(1):e00291. doi:10.1136/lupus-2018-000291

6. Werth VP, White WL, Sanchez MR, Franks AG. Incidence of alopecia areata in lupus erythematosus. Arch Dermatol. 1992;128 (3):368-371. doi:10.1001/archderm.1992.01680130082010

7. Yun SJ, Lee JW, Yoon HJ, et al. Cross-sectional study of hair loss patterns in 122 Korean systemic lupus erythematosus patients: a frequent finding of non-scarring patch alopecia. $J$ Dermatol. 2007;34(7):451-455. doi:10.1111/j.1346-8138.2007.00309.x

8. Chanprapaph K, Udompanich S, Visessiri Y, Ngamjanyaporn P, Suchonwanit P. Nonscarring alopecia in systemic lupus erythematosus: a cross-sectional study with trichoscopic, histopathologic, and immunopathologic analyses. J Am Acad Dermatol. 2019;81(6):1319-1329. doi:10.1016/j.jaad.2019.05.053

9. Maeshima K, Shibata H. Efficacy of JAK $1 / 2$ inhibition in the treatment of diffuse non-scarring alopecia due to systemic lupus erythematosus. Ann Rheum Dis. 2020;79(5):674-675. doi:10.1136/annrheumdis-2019-216571

10. Petri M, Orbai AM, Alarcón GS, et al. Derivation and validation of the Systemic Lupus International Collaborating Clinics classification criteria for systemic lupus erythematosus. Arthritis Rheum. 2012;64(8):2677-2686. doi:10.1002/art.34473 
11. Bolduc C, Sperling LC, Shapiro J. Primary cicatricial alopecia: lymphocytic primary cicatricial alopecias, including chronic cutaneous lupus erythematosus, lichen planopilaris, frontal fibrosing alopecia, and Graham-Little syndrome. J Am Acad Dermatol. 2016;75(6):1081-1099.

12. Hamilton $\mathrm{T}$, Otberg $\mathrm{N}, \mathrm{Wu} \mathrm{WY}$, Martinka M, Shapiro J. Successful hair re-growth with multimodal treatment of early cicatricial alopecia in discoid lupus erythematosus. Acta Derm Venereol. 2009;89(4):417-418. doi:10.2340/00015555-0643

13. Milam EC, Ramachandran S, Franks AG Jr. Treatment of scarring alopecia in discoid variant of chronic cutaneous lupus erythematosus with tacrolimus lotion, 0.3. JAMA Dermatol. 2015;151 (10):1113-1116. doi:10.1001/jamadermatol.2015.1349

14. Chung HJ, Goldberg LJ. Histologic features of chronic cutaneous lupus erythematosus of the scalp using horizontal sectioning: emphasis on follicular findings. J Am Acad Dermatol. 2017;77 (2):349-355. doi:10.1016/j.jaad.2017.02.039

15. Diaz A, Miteva M. Pigmented lesions on the scalp in a healthy woman. Int J Dermatol. 2020;59(7):e231-e233. doi:10.1111/ ijd. 14714

16. Olivry T, Linder KE, Banovic F. Cutaneous lupus erythematosus in dogs: a comprehensive review. BMC Vet Res. 2018;14(1):132. doi:10.1186/s12917-018-1446-8

17. Elman SA, Joyce $\mathrm{C}$, Braudis $\mathrm{K}$, et al. Creation and validation of classification criteria for discoid lupus erythematosus. JAMA Dermatol. 2020;156(8):901-906. doi:10.1001/ jamadermatol.2020.1698

18. Cervantes J, Hafeez F, Miteva M. Blue-white veil as novel dermatoscopic feature in discoid lupus erythematosus in 2 African-American patients. Skin Appendage Disord. 2017;3 (4):211-214. doi:10.1159/000477354

19. Estrada BD, Tamler C, Sodré CT, Barcaui CB, Pereira FB. Dermoscopy patterns of cicatricial alopecia resulting from discoid lupus erythematosus and lichen planopilaris. An Bras Dermatol. 2010;85(2):179-183. doi:10.1590/s0365-05962010000200008

20. Kossard S. Lupus panniculitis clinically simulating alopecia areata. Australas J Dermatol. 2002;43(3):221-223. doi:10.1046/ j.1440-0960.2002.00601.x

21. Udompanich S, Chanprapaph K, Suchonwanit P. Hair and scalp changes in cutaneous and systemic lupus erythematosus. Am J Clin Dermatol. 2018;19(5):679-694. doi:10.1007/s40257-018-0363-8

22. Ye Y, Zhao Y, Gong Y, et al. Non-scarring patchy alopecia in patients with systemic lupus erythematosus differs from that of alopecia areata. Lupus. 2013;22(14):1439-1445. doi:10.1177/ 0961203313508833

23. Suchonwanit P, Udompanich S, Thadanipon K, Chanprapaph K. Trichoscopic signs in systemic lupus erythematosus: a comparative study with 109 patients and 305 healthy controls. J Eur Acad Dermatol Venereol. 2019;33(4):774-780. doi:10.1111/jdv.15421

24. Mubki T, Rudnicka L, Olszewska M, Shapiro J. Evaluation and diagnosis of the hair loss patient: part I. History and clinical examination. J Am Acad Dermatol. 2014;71(3):415.e411-415. e415. doi:10.1016/j.jaad.2014.04.070

25. Rai VM, Balachandran C. Subacute cutaneous lupus erythematosus (SCLE) presenting in childhood. Dermatol Online J. 2005;11(2):27.

26. Hoverson K, Jarell AD, Wohltmann WE. Lupus erythematosus tumidus of the scalp masquerading as alopecia areata. Cutis. 2017;99(2):E22-E24.

27. Singh AH, Werth VP. Alopecia associated with papulonodular mucinosis (tumid) lesions of lupus erythematosus. J Clin Rheumatol. 1997;3(6):343-345. doi:10.1097/00124743199712000-00008

28. Chen YA, Hsu CK, Lee JY, Yang CC. Linear lupus panniculitis of the scalp presenting as alopecia along Blaschko's lines: a distinct variant of lupus panniculitis in East Asians? J Dermatol. 2012;39 (4):385-388. doi:10.1111/j.1346-8138.2011.01455.x
29. Grossberg E, Scherschun L, Fivenson DP. Lupus profundus: not a benign disease. Lupus. 2001;10(7):514-516. doi:10.1191/ 096120301678416105

30. Lueangarun S, Subpayasarn U, Tempark T. Distinctive lupus panniculitis of scalp with linear alopecia along Blaschko's lines: a review of the literature. Int J Dermatol. 2019;58(2):144-150. doi:10.1111/ijd.14155

31. Goldberg LJ, Sekhri V, Bhawan J. Dermal mucin in alopecia areata-tell tale sign or incidental finding? J Cutan Pathol. 2008;35(8):757-760. doi:10.1111/j.1600-0560.2007.00875.x

32. Fairley JL, Oon S, Saracino AM, Nikpour M. Management of cutaneous manifestations of lupus erythematosus: a systematic review. Semin Arthritis Rheum. 2020;50(1):95-127. doi:10.1016/ j.semarthrit.2019.07.010

33. Jessop S, Whitelaw DA, Grainge MJ, Jayasekera P. Drugs for discoid lupus erythematosus. Cochrane Database Syst Rev. 2017;5(5):Cd002954. doi:10.1002/14651858.CD002954.pub3

34. Albrecht J, Taylor L, Berlin JA, et al. The CLASI (Cutaneous Lupus Erythematosus Disease Area and Severity Index): an outcome instrument for cutaneous lupus erythematosus. J Invest Dermatol. 2005;125(5):889-894. doi:10.1111/j.0022-202X.2005.23889.x

35. Ismail FF, Meah N, Sinclair R. Reversibility of alopecia caused by chronic cutaneous lupus erythematosus. Int $J$ Dermatol. 2020;59(12):e437-e438. doi:10.1111/ijd.15148

36. Kuhn A, Aberer E, Bata-Csörgő Z, et al. S2k guideline for treatment of cutaneous lupus erythematosus - guided by the European Dermatology Forum (EDF) in cooperation with the European Academy of Dermatology and Venereology (EADV). J Eur Acad Dermatol Venereol. 2017;31(3):389-404. doi:10.1111/ jdv. 14053

37. Garza-Mayers AC, McClurkin M, Smith GP. Review of treatment for discoid lupus erythematosus. Dermatol Ther. 2016;29 (4):274-283. doi:10.1111/dth.12358

38. Zahn S, Graef M, Patsinakidis N, et al. Ultraviolet light protection by a sunscreen prevents interferon-driven skin inflammation in cutaneous lupus erythematosus. Exp Dermatol. 2014;23 (7):516-518. doi:10.1111/exd.12428

39. Miot HA, Miot LDB, Haddad GR. Association between discoid lupus erythematosus and cigarette smoking. Dermatology. 2005;211(2):118-122. doi:10.1159/000086440

40. Piette EW, Foering KP, Chang AY, et al. Impact of smoking in cutaneous lupus erythematosus. Arch Dermatol. 2012;148 (3):317-322. doi:10.1001/archdermatol.2011.342

41. Chasset F, Francès C, Barete S, Amoura Z, Arnaud L. Influence of smoking on the efficacy of antimalarials in cutaneous lupus: a meta-analysis of the literature. J Am Acad Dermatol. 2015;72 (4):634-639. doi:10.1016/j.jaad.2014.12.025

42. Chasset F, Tounsi T, Cesbron E, Barbaud A, Francès C, Arnaud L. Efficacy and tolerance profile of thalidomide in cutaneous lupus erythematosus: a systematic review and meta-analysis. $J$ Am Acad Dermatol. 2018;78(2):342-350.e344. doi:10.1016/j.jaad.2017.09.059

43. Chasset F, Francès C. Current concepts and future approaches in the treatment of cutaneous lupus erythematosus: a comprehensive review. Drugs. 2019;79(11):1199-1215. doi:10.1007/s40265-019-01151-8

44. Bacanli A, Uzun S, Ciftcioglu MA, Alpsoy E. A case of lupus erythematosus profundus with unusual manifestations. Lupus. 2005;14(5):403-405. doi:10.1191/0961203305lu2088cr

45. Kindle SA, Wetter DA, Davis MD, Pittelkow MR, Sciallis GF. Lenalidomide treatment of cutaneous lupus erythematosus: the Mayo Clinic experience. Int J Dermatol. 2016;55(8):e431-e439. doi:10.1111/ijd.13226

46. Klein A, Vogt $\mathrm{T}$, Wenzel SM, Fleck M, Landthaler M. Cyclosporin combined with methotrexate in two patients with recalcitrant subacute cutaneous lupus erythematosus. Australas J Dermatol. 2011;52(1):43-47. doi:10.1111/j.14400960.2010.00689.x 
47. Kuhn A, Patsinakidis N, Luger T. Alitretinoin for cutaneous lupus erythematosus. J Am Acad Dermatol. 2012;67(3):e123-e126. doi:10.1016/j.jaad.2011.10.030

48. Park KY, Lee JW, Li K, Seo SJ, Hong CK. Treatment of refractory discoid lupus erythematosus using 1064-nm long-pulse neodymium-doped yttrium aluminum garnet laser. Dermatol Surg. 2011;37(7):1055-1056. doi:10.1111/j.15244725.2011.02019.x

49. Tenti S, Fabbroni M, Mancini V, Russo F, Galeazzi M, Fioravanti A. Intravenous immunoglobulins as a new opportunity to treat discoid lupus erythematosus: a case report and review of the literature. Autoimmun Rev. 2018;17(8):791-795. doi:10.1016/ j.autrev.2018.02.010

50. Cortés-Hernández J, Ávila G, Vilardell-Tarrés M, Ordi-Ros J. Efficacy and safety of lenalidomide for refractory cutaneous lupus erythematosus. Arthritis Res Ther. 2012;14(6):R265. doi:10.1186/ar4111

51. Tan E, Martinka M, Ball N, Shapiro J. Primary cicatricial alopecias: clinicopathology of 112 cases. J Am Acad Dermatol. 2004;50(1):25-32. doi:10.1016/j.jaad.2003.04.001

52. Yokogawa N, Eto H, Tanikawa A, et al. Effects of hydroxychloroquine in patients with cutaneous lupus erythematosus: a multicenter, double-blind, randomized, parallel-group trial. Arthritis Rheumatol. 2017;69(4):791-799. doi:10.1002/art.40018

53. Dörner T. Therapy: hydroxychloroquine in SLE: old drug, new perspectives. Nat Rev Rheumatol. 2010;6(1):10-11. doi:10.1038/ nrrheum.2009.235

54. Pons-Estel GJ, Alarcón GS, González LA, et al. Possible protective effect of hydroxychloroquine on delaying the occurrence of integument damage in lupus: LXXI, data from a multiethnic cohort. Arthritis Care Res (Hoboken). 2010;62(3):393-400. doi:10.1002/acr.20097

55. Wahie S, Meggitt SJ. Long-term response to hydroxychloroquine in patients with discoid lupus erythematosus. $\mathrm{Br} J$ Dermatol. 2013;169(3):653-659. doi:10.1111/bjd.12378

56. Chang AY, Piette EW, Foering KP, Tenhave TR, Okawa J, Werth VP. Response to antimalarial agents in cutaneous lupus erythematosus: a prospective analysis. Arch Dermatol. 2011;147 (11):1261-1267. doi:10.1001/archdermatol.2011.191

57. Igari S, Yamamoto T. Dramatic effect of hydroxychloroquine on lupus alopecia. J Dermatol. 2018;45(2):194-197. doi:10.1111/ 1346-8138.14069

58. Lehrhoff S, Tzu J, Patel R, Sanchez M, Franks AG Jr. Lupus erythematosus tumidus with discoid lupus erythematosus-induced alopecia of the scalp. Dermatol Online J. 2011;17(10):24.

59. Tran B, Yazdani Abyaneh MA, Wu J. Rapid response to treatment with thalidomide in an adolescent with generalized discoid lupus erythematosus. Pediatr Dermatol. 2020;37(1):244-245. doi: $10.1111 /$ pde. 14067

60. Ding HJ, Denniston AK, Rao VK, Gordon C. Hydroxychloroquine-related retinal toxicity. Rheumatology (Oxford). 2016;55(6):957-967. doi:10.1093/rheumatology/ $\operatorname{kev} 357$

61. Avgerinou G, Papafragkaki DK, Nasiopoulou A, Arapaki A, Katsambas A, Stavropoulos PG. Effectiveness of topical calcineurin inhibitors as monotherapy or in combination with hydroxychloroquine in cutaneous lupus erythematosus. $J$ Eur Acad Dermatol Venereol. 2012;26(6):762-767. doi:10.1111/j.14683083.2011.04161.x

62. Barikbin B, Givrad S, Yousefi M, Eskandari F. Pimecrolimus 1\% cream versus betamethasone 17 -valerate $0.1 \%$ cream in the treatment of facial discoid lupus erythematosus: a double-blind, randomized pilot study. Clin Exp Dermatol. 2009;34(7):776-780. doi:10.1111/j.1365-2230.2008.03138.x
63. Kuhn A, Gensch K, Haust M, et al. Efficacy of tacrolimus $0.1 \%$ ointment in cutaneous lupus erythematosus: a multicenter, randomized, double-blind, vehicle-controlled trial. $J$ Am Acad Dermatol. 2011;65(1):54-64, 64.e51-e52. doi:10.1016/j. jaad.2010.03.037

64. de la Rosa Carrillo D, Christensen OB. Treatment of chronic discoid lupus erythematosus with topical tacrolimus. Acta Derm Venereol. 2004;84(3):233-234. doi:10.1080/ 00015550310007698

65. Company-Quiroga J, Alique-García S, Romero-Maté A. Current insights into the management of discoid lupus erythematosus. Clin Cosmet Investig Dermatol. 2019;12:721-732. doi:10.2147/ CCID.S184824

66. Jemec GB, Ullman S, Goodfield $\mathrm{M}$, et al. A randomized controlled trial of R-salbutamol for topical treatment of discoid lupus erythematosus. $\mathrm{Br} J$ Dermatol. 2009;161(6):1365-1370. doi:10.1111/j.1365-2133.2009.09330.x

67. Wulf HC, Ullman S. Discoid and subacute lupus erythematosus treated with 0.5\% R-salbutamol cream. Arch Dermatol. 2007;143 (12):1589-1590. doi:10.1001/archderm.143.12.1589

68. Edwards KR, Burke WA. Treatment of localized discoid lupus erythematosus with tazarotene. J Am Acad Dermatol. 1999;41 (6):1049-1050. doi:10.1016/S0190-9622(99)70278-1

69. Terao M, Matsui S, Katayama I. Two cases of refractory discoid lupus erythematosus successfully treated with topical tocoretinate. Dermatol Online J. 2011;17(4):15.

70. D’Erme AM, Milanesi N, Difonzo EM, Lotti T, Gola M. Treatment of refractory subacute cutaneous lupus erythematosus with oral isotretinoin: a valid therapeutic option Dermatol Ther. 2012;25(3):281-282. doi:10.1111/j.1529_ 8019.2012.01461.x

71. Ruzicka T, Sommerburg C, Goerz G, Kind P, Mensing H. Treatment of cutaneous lupus erythematosus with acitretin and hydroxychloroquine. $\mathrm{Br} J$ Dermatol. 1992;127(5):513-518. doi:10.1111/j.1365-2133.1992.tb14851.x

72. Narang T, Sharma M, Gulati N, Kaur A. Extensive hypertrophic lupus erythematosus: atypical presentation. Indian $J$ Dermatol. 2012;57(6):504.

73. Shornick JK, Formica N, Parke AL. Isotretinoin for refractory lupus erythematosus. J Am Acad Dermatol. 1991;24(1):49-52. doi:10.1016/0190-9622(91)70008-P

74. Fruchter R, Kurtzman DJB, Patel M, et al. Characteristics and alternative treatment outcomes of antimalarial-refractory cutaneous lupus erythematosus. JAMA Dermatol. 2017;153 (9):937-939. doi:10.1001/jamadermatol.2017.1160

75. Islam MN, Hossain M, Haq SA, Alam MN, Ten Klooster PM, Rasker JJ. Efficacy and safety of methotrexate in articular and cutaneous manifestations of systemic lupus erythematosus. Int $J$ Rheum Dis. 2012;15(1):62-68. doi:10.1111/j.1756185X.2011.01665.x

76. Klebes M, Wutte N, Aberer E. Dapsone as second-line treatment for cutaneous lupus erythematosus? A retrospective analysis of 34 patients and a review of the literature. Dermatology. 2016;232 (1):91-96. doi:10.1159/000441054

77. Fernandez-Flores A, Hermosa-Gelbard A, Pérez A, Bello JA, Cabo F. Scarring alopecia in chronic cutaneous lupus erythematosus with neutrophils: a new scenario with therapeutic connotations. J Cutan Pathol. 2020;47(10):976-982. doi:10.1111/cup. 13764

78. Gammon B, Hansen C, Costner MI. Efficacy of mycophenolate mofetil in antimalarial-resistant cutaneous lupus erythematosus. J Am Acad Dermatol. 2011;65(4):717-721.e712. doi:10.1016/j. jaad.2010.08.011 
79. Goyal S, Nousari HC. Treatment of resistant discoid lupus erythematosus of the palms and soles with mycophenolate mofetil. $\mathrm{J} \mathrm{Am}$ Acad Dermatol. 2001;45(1):142-144. doi:10.1067/ mjd.2001.114297

80. Kreuter A, Tomi NS, Weiner SM, Huger M, Altmeyer P, Gambichler T. Mycophenolate sodium for subacute cutaneous lupus erythematosus resistant to standard therapy. $\mathrm{Br}$ $J$ Dermatol. 2007;156(6):1321-1327. doi:10.1111/j.13652133.2007.07826.x

81. Pisoni CN, Obermoser G, Cuadrado MJ, et al. Skin manifestations of systemic lupus erythematosus refractory to multiple treatment modalities: poor results with mycophenolate mofetil. Clin Exp Rheumatol. 2005;23(3):393-396.

82. Cortés-Hernández J, Torres-Salido M, Castro-Marrero J, Vilardell-Tarres M, Ordi-Ros J. Thalidomide in the treatment of refractory cutaneous lupus erythematosus: prognostic factors of clinical outcome. $\mathrm{Br} \quad J$ Dermatol. 2012;166(3):616-623. doi:10.1111/j.1365-2133.2011.10693.x

83. Baret I, De Haes P. Thalidomide: still an important second-line treatment in refractory cutaneous lupus erythematosus? $J$ Dermatolog Treat. 2015;26(2):173-177. doi:10.3109/ 09546634.2014.906036

84. Okon L, Rosenbach M, Krathen M, et al. Lenalidomide in treatment-refractory cutaneous lupus erythematosus: efficacy and safety in a 52-week trial. J Am Acad Dermatol. 2014;70 (3):583-584. doi:10.1016/j.jaad.2013.11.007

85. Aitmehdi R, Arnaud L, Francès C, et al. Long-term efficacy and safety outcomes of lenalidomide for cutaneous lupus erythematosus: a multicenter retrospective observational study of 40 patients. J Am Acad Dermatol. 2020. doi:10.1016/j.jaad.2020.11.014

86. Wu EY, Schanberg LE, Wershba EC, Rabinovich CE. Lenalidomide for refractory cutaneous manifestations of pediatric systemic lupus erythematosus. Lupus. 2017;26(6):646-649. doi:10.1177/0961203316676377

87. Kuhn A, Landmann A, Bonsmann G. Fumaric acid esters: a new therapeutic option for skin manifestations in lupus erythematosus? $\quad \mathrm{Br} \quad J$ Dermatol. 2017;176(2):301-302. doi:10.1111/bjd.14938

88. Saracino AM, Orteu CH. Severe recalcitrant cutaneous manifestations in systemic lupus erythematosus successfully treated with fumaric acid esters. $B r J$ Dermatol. 2017;176(2):472-480. doi:10.1111/bjd.14698

89. De Souza A, Strober BE, Merola JF, Oliver S, Franks AG Jr. Apremilast for discoid lupus erythematosus: results of a Phase 2, open-label, single-arm, pilot study. J Drugs Dermatol. 2012;11 (10):1224-1226.

90. Callen JP, Spencer LV, Burruss JB, Holtman J. Azathioprine: an effective, corticosteroid-sparing therapy for patients with recalcitrant cutaneous lupus erythematosus or with recalcitrant cutaneous leukocytoclastic vasculitis. Arch Dermatol. 1991;127 (4):515-522. doi:10.1001/archderm.1991.04510010083008

91. Yell JA, Burge SM. Cyclosporin and discoid lupus erythematosus. Br J Dermatol. 1994;131(1):132-133. doi:10.1111/j.13652133.1994.tb08471.x

92. Lampropoulos CE, Hughes GR, D'Cruz DP. Intravenous immunoglobulin in the treatment of resistant subacute cutaneous lupus erythematosus: a possible alternative. Clin Rheumatol. 2007;26 (6):981-983. doi:10.1007/s10067-006-0222-5

93. Ky C, Swasdibutra B, Khademi S, Desai S, Laquer V, Grando SA. Efficacy of intravenous immunoglobulin monotherapy in patients with cutaneous lupus erythematosus: results of Proof-of-Concept Study. Dermatol Rep. 2015;7(1):5804. doi:10.4081/dr.2015.5804

94. Wallace DJ, Furie RA, Tanaka Y, et al. Baricitinib for systemic lupus erythematosus: a double-blind, randomised, placebo-controlled, phase 2 trial. Lancet. 2018;392 (10143):222-231. doi:10.1016/S0140-6736(18)31363-1
95. Yuan K, Huang G, Sang X, Xu A. Baricitinib for systemic lupus erythematosus. Lancet. 2019;393(10170):402. doi:10.1016/ S0140-6736(18)32763-6

96. Iaccarino L, Andreoli L, Bocci EB, et al. Clinical predictors of response and discontinuation of belimumab in patients with systemic lupus erythematosus in real life setting. Results of a large, multicentric, nationwide study. $J$ Autoimmun. 2018;86:1-8. doi:10.1016/j.jaut.2017.09.004

97. Wenzel J, Landmann A, Vorwerk G, Kuhn A. High expression of B lymphocyte stimulator in lesional keratinocytes of patients with cutaneous lupus erythematosus. Exp Dermatol. 2018;27 (1):95-97. doi:10.1111/exd.13419

98. Manzi S, Sánchez-Guerrero J, Merrill JT, et al. Effects of belimumab, a B lymphocyte stimulator-specific inhibitor, on disease activity across multiple organ domains in patients with systemic lupus erythematosus: combined results from two phase III trials. Ann Rheum Dis. 2012;71(11):1833-1838. doi:10.1136/annrheumdis-2011-200831

99. Vashisht $\mathrm{P}$, Borghoff $\mathrm{K}$, O’Dell JR, Hearth-Holmes M. Belimumab for the treatment of recalcitrant cutaneous lupus. Lupus. 2017;26(8):857-864. doi:10.1177/0961203316682097

100. Quelhas da Costa R, Aguirre-Alastuey ME, Isenberg DA, Saracino AM. Assessment of response to B-cell depletion using rituximab in cutaneous lupus erythematosus. JAMA Dermatol. 2018;154(12):1432-1440. doi:10.1001/jamadermatol.2018.3793

101. Vital EM, Wittmann M, Edward S, et al. Brief report: responses to rituximab suggest $\mathrm{B}$ cell-independent inflammation in cutaneous systemic lupus erythematosus. Arthritis Rheumatol. 2015;67(6):1586-1591. doi:10.1002/art.39085

102. van Vollenhoven RF, Hahn BH, Tsokos GC, et al. Efficacy and safety of ustekinumab, an IL-12 and IL-23 inhibitor, in patients with active systemic lupus erythematosus: results of a multicentre, double-blind, phase 2, randomised, controlled study. Lancet. 2018;392(10155):1330-1339. doi:10.1016/S01406736(18)32167-6

103. Dahl C, Johansen C, Kragballe K, Olesen AB. Ustekinumab in the treatment of refractory chronic cutaneous lupus erythematosus: a case report. Acta Derm Venereol. 2013;93(3):368-369. doi:10.2340/00015555-1467

104. De Souza A, Ali-Shaw T, Strober BE, Franks AG Jr. Successful treatment of subacute lupus erythematosus with ustekinumab. Arch Dermatol. 2011;147(8):896-898. doi:10.1001/ archdermatol.2011.185

105. Romero-Maté A, García-Donoso C, Hernández-Núñez A, Martínez-Morán C, Moreno-Torres A, Borbujo-Martínez J. Successful treatment of recalcitrant discoid lupus erythematosus with ustekinumab. Dermatol Online J. 2017;23(1).

106. Varada S, Gottlieb AB, Merola JF, Saraiya AR, Tintle SJ. Treatment of coexistent psoriasis and lupus erythematosus. $J$ Am Acad Dermatol. 2015;72(2):253-260. doi:10.1016/j.jaad.2014.10.038

107. Tanasescu C, Balanescu E, Balanescu P, et al. IL-17 in cutaneous lupus erythematosus. Eur J Intern Med. 2010;21(3):202-207. doi:10.1016/j.ejim.2010.03.004

108. Furie R, Werth VP, Merola JF, et al. Monoclonal antibody targeting BDCA2 ameliorates skin lesions in systemic lupus erythematosus. J Clin Invest. 2019;129(3):1359-1371. doi:10.1172/JCI124466

109. Furie R, Khamashta M, Merrill JT, et al. Anifrolumab, an antiinterferon- $\alpha$ receptor monoclonal antibody, in moderate-to-severe systemic lupus erythematosus. Arthritis Rheumatol. 2017;69 (2):376-386. doi:10.1002/art.39962

110. Merrill JT, Furie R, Werth VP, et al. Anifrolumab effects on rash and arthritis: impact of the type I interferon gene signature in the phase IIb MUSE study in patients with systemic lupus erythematosus. Lupus Sci Med. 2018;5(1):e000284. doi:10.1136/ lupus-2018-000284 
111. Khamashta M, Merrill JT, Werth VP, et al. Sifalimumab, an antiinterferon- $\alpha$ monoclonal antibody, in moderate to severe systemic lupus erythematosus: a randomised, double-blind, placebocontrolled study. Ann Rheum Dis. 2016;75(11):1909-1916. doi:10.1136/annrheumdis-2015-208562

112. Werth VP, Fiorentino D, Sullivan BA, et al. Brief report: pharmacodynamics, safety, and clinical efficacy of AMG 811, a human antiinterferon- $\gamma$ antibody, in patients with discoid lupus erythematosus. Arthritis Rheumatol. 2017;69(5):1028-1034. doi:10.1002/art.40052

113. Brauer JA, Gordon Spratt EA, Geronemus RG. Laser therapy in the treatment of connective tissue diseases: a review. Dermatol Surg. 2014;40(1):1-13. doi:10.1111/dsu.12339

114. Byun YS, Son JH, Cho YS, et al. Intense pulsed light and Q-Switched 1064-nm neodymium-doped yttrium aluminum garnet laser treatment for the scarring lesion of discoid lupus erythematosus. Ann Dermatol. 2017;29(3):331-333. doi:10.5021/ad.2017.29.3.331

115. Ekbäck MP, Troilius A. Laser therapy for refractory discoid lupus erythematosus when everything else has failed. J Cosmet Laser Ther. 2013;15(5):260-265. doi:10.3109/14764172.2013.787802

116. Erceg A, Bovenschen HJ, van de Kerkhof PC, de Jong EM, Seyger MM. Efficacy and safety of pulsed dye laser treatment for cutaneous discoid lupus erythematosus. J Am Acad Dermatol. 2009;60(4):626-632. doi:10.1016/j.jaad.2008.11.904
117. Rerknimitr P, Tekacharin N, Panchaprateep R, et al. Pulsed-dye laser as an adjuvant treatment for discoid lupus erythematosus: a randomized, controlled trial. J Dermatolog Treat. 2019;30 (1):81-86. doi:10.1080/09546634.2018.1468063

118. Truchuelo MT, Boixeda P, Alcántara J, Moreno C, de Las Heras E, Olasolo PJ. Pulsed dye laser as an excellent choice of treatment for lupus tumidus: a prospective study. J Eur Acad Dermatol Venereol. 2012;26(10):1272-1279. doi:10.1111/j.14683083.2011.04281.x

119. Ekelem C, Pham C, Atanaskova Mesinkovska N. A systematic review of the outcome of hair transplantation in primary scarring alopecia. Skin Appendage Disord. 2019;5(2):65-71. doi:10.1159/ 000492539

120. Nordström RE. Hair transplantation. The use of hairbearing compound grafts for correction of alopecia due to chronic discoid lupus erythematosus, traumatic alopecia, and male pattern baldness. Scand J Plast Reconstr Surg Suppl. 1976;14:1-37.

\section{Publish your work in this journal}

Clinical, Cosmetic and Investigational Dermatology is an international, peer-reviewed, open access, online journal that focuses on the latest clinical and experimental research in all aspects of skin disease and cosmetic interventions. This journal is indexed on CAS.
The manuscript management system is completely online and includes a very quick and fair peer-review system, which is all easy to use. Visit http://www.dovepress.com/testimonials.php to read real quotes from published authors. 